\title{
Extracorporeal membrane oxygenation in life-threatening asthma unresponsive to mechanical ventilation: $a$ comparison of patient demographics and outcomes between a large London-based intensive care unit and an international registry
}

\author{
Authors: Kritchai Vutipongsatorn, ${ }^{A}$ Eri Fujitake ${ }^{A}$ and Suveer Singh ${ }^{B}$
}

\section{Introduction}

According to the British Thoracic Society (BTS) guidelines, ${ }^{1}$ extracorporeal membrane oxygenation (ECMO) may be considered in near-fatal asthma exacerbations refractory to conventional ventilator treatment. However, there is currently no clear criteria for accepting such patients for ECMO treatment. The comparison of local data to an internationally established database would lead to a better insight into optimal criteria for the commencement of ECMO treatment.

\section{Methods}

Medical records of asthmatic patients who were admitted to Royal Brompton Hospital (RBH) for ECMO from 2012 to 2018 were reviewed. Parameters such as pre- and post-ECMO blood gases, ventilator settings and outcomes were calculated and compared with the Extracorporeal Life Support Organization (ELSO) registry, ${ }^{2}$ an international database for ECMO from 1992 to 2016 ( $n=272$ ).

\section{Results and discussion}

Ten patients ( $38.4 \pm 13.6$ years) were identified. Sixty per cent were known asthmatics, and $40 \%$ had previous hospital admissions for asthma. Eighty per cent had an infective trigger. The mean duration on ECMO and stay on intensive treatment unit (ITU) were $6.7 \pm 2.9$ days and $11.9 \pm 5.3$ days, respectively. Compared with the ELSO registry, there were no significant differences in patient demographics. Prior to ECMO, RBH patients were significantly more hypercapnic ( 16.0 vs $10.7 \mathrm{kPa}, \mathrm{p}=0.014$ ), and were on a significantly less aggressive ventilator setting with regards to $\mathrm{FiO}_{2}(57.1 \%$ vs $81.2 \%, p=0.002)$ and positive end-expiratory pressure (PEEP) $(4.3$ vs $8.3 \mathrm{kPa}, \mathrm{p}=0.043)$. However, there were no significant differences in survival $(100 \%$ vs $83.5 \%, p=0.363)$ or duration on ECMO $(6.7$

Authors: ${ }^{\mathrm{A} I m p e r i a l ~ C o l l e g e ~ L o n d o n, ~ U K ; ~}{ }^{\mathrm{B}}$ Royal Brompton Hospital, London, UK vs 7.4 days, $p=0.785)$. The pre-ECMO blood gas and ventilation settings could indicate a higher threshold for commencing ECMO in the $\mathrm{RBH}$ cohort, or the result of less aggressive ventilation settings prior to starting ECMO. However, this had no impact on survival and duration on ECMO.

\section{Conclusion}

Despite similar outcomes, there are significant differences in the $\mathrm{RBH}$ cohort with regards to the pre-ECMO ventilation settings and blood gases. As recommended by the BTS, further research of a bigger sample size is required to improve understanding of treatment-refractory fatal asthma.

\section{Conflict of interest statement}

None declared.

\section{References}

1 British Thoracic Society and Scottish Intercollegiate Guidelines Network. British Guideline on the management of asthma. BTS, 2016. www.brit-thoracic.org.uk/document-library/clinical-information/asthma/btssign-guideline-on-the- management-of-asthma/ [Accessed 21 February 2019].

2 Yeo HJ, Kim D, Jeon D, Kim YS, Rycus P, Cho WH. Extracorporeal membrane oxygenation for life-threatening asthma refractory to mechanical ventilation: analysis of the Extracorporeal Life Support Organization registry. Crit Care 2017;21:297 